\title{
A REPRESENTAÇÃO LITERÁRIA DE LAMPIÃO EM RACHEL DE QUEIROZ: NUANCES DE AUTORITARISMO
}

\author{
Maria Edileuza Costa ${ }^{1}$ \\ Irio José do Nascimento Germano Júnior ${ }^{2}$
}

Resumo: Este trabalho tem como objetivo analisar a representação literária da personagem Lampião com foco na construção da identidade na obra literária Lampião (2005), de Rachel de Queiroz. Buscarse-á, para a leitura da obra, contribuições teóricas que envolvem história, autoritarismo, e crítica, relacionada ao contexto social no qual está inserido o texto literário. O teatro de Rachel de Queiroz trata da história de Virgulino Ferreira da Silva e ressalta sua vida de cangaceiro ao lado dos seus jagunços e com Maria Déa, mais conhecida como Maria Bonita. Dessa maneira, o enredo da peça supracitada apresenta identidades fragmentadas. Percebemos, nessa perspectiva, crenças, hábitos e ações nas quais o caráter e comportamentos dos cangaceiros tomam forma "exclusa" da ótica social.

Palavras-chave: Lampião; representação Literária; autoritarismo.

Abstract: This work aims at analyzing literary representation about Lampião (2005), a northern Brazilian famous character created by the writer, Rachel de Queiroz. We did search a kind of reading of the book trying to understand theoretical contributions that go around history, culture, identity, and critics about social context in what is concerned to literature about Lampião. The theater produced by Raquel de Queiroz leads with the History of Virgulino Ferreira da Silva - called Lampião, and it gives focus on his life by the side of his partners (outlaws) and Lampião's lover, Maria Déa, she was known by Maria Bonita. In this way, the plot of the above-mentioned piece presents fragmented identities. In this perspective, we perceive beliefs, habits and actions in which the characters and behaviors of the cangaceiros take the form "excluded" from the social perspective.

Keywords: Lampião; Literary representation; authoritarianism.

1 Professora e coordenadora do programa de pós-graduação de Letras (PPGL/UERN). E-mail: edileuzacostauern@gmail. com.

2 Mestrando área de concentração: Estudos do Discurso e do Texto, com linha de pesquisa em: Discurso, Memória e Identidade (PPGL/UERN). E-mail: iriogermano@gmail.com. 


\section{INTRODUÇÃO}

A literatura, em tese, torna-se uma infindável fonte profícua de sabedoria. Possibilita ao ser humano representações coadunadas em anseios, altercações, redizeres e questionamentos direcionados na sociedade em que são marcados por um contexto sócio-histórico. Desta maneira, a literatura percorre por um vínculo, por uma interação que é produto do ensejo artístico e da situação geradora da obra. Fica patente, desse modo, realizar uma espécie de intertextualidade. Na qual pode-se estender aproximações significativas com outros textos que permeia o artista. Nesta concepção, analisar a literatura corresponde, grosso modo, em se fazer um diálogo/inter-relação do contexto externo circundado no interno. $\mathrm{O}$ estudioso apresenta uma consideração compatível com o que se tem dito: Massaud Moisés (1997, p. 159), "espelho fiel dum povo, a imagem fiel duma sociedade”, configura-se, assim, perceber os vastos sentidos brotados através da literatura quando o lemos. Ao Levar em consideração como objeto de produção os aspectos sociais, históricos, culturais dos indivíduos e, com isso, ajudando a notar as suas mazelas vigentes. Logo mais, os textos literários, no que diz respeito ao processo histórico, possuem um olhar contínuo, em evolução, pois o teor seletivo, ideológico e escrito das obras não são imutáveis e estão em constante transformação e duradouras com as raízes históricas literárias. Conforme aponta Bueno: "Em outras palavras, a ideia de que a literatura, vista sob o ponto de vista histórico, [...], vê a tradição literária como algo em andamento e não um objeto estático capaz de ser capturado e congelado sem traumas num livro de histórias literária. ” (2006, p.15).

Diante disso, neste trabalho, propomos analisar a representação literária da personagem Lampião com foco na construção/processo de exclusa e autoritarismo com os cangaceiros junto com sua parceira Maria Bonita. $\mathrm{Na}$ qual, mesmo cingidos em hastes autoritaristas do governo, sobressaem por meio de suas ideologias invitadas através da peça Lampião (2005), de Rachel de Queiroz. Além do mais, esta pesquisa é bibliográfica de caráter qualitativo, já que analisa o conteúdo através do objeto de estudo, neste caso, com base no livro ou obra literária.

Concomitantemente, percebermos que arte literária, grosso modo, carrega consigo uma impressão subjetiva em que se encontra o povo e a sociedade. No Nordeste, uma marca que pode acompanhar e revestir a imagem dos seus habitantes em seu espaço é o cangaço. $\mathrm{O}$ termo cangaço conforme aponta Dória (1882, p. 24), se refere ao "nome dado ao armamento do indivíduo que andava de bacamarte passado sobre os ombros, tal qual boi no jugo, sobrecarregando ainda uma quantidade de outras armas". Exploremos, assim, traços de personalidade que não se resumem a um único indivíduo, mas a uma representação coletiva das demais personagens. A obra Lampião é uma uma peça teatral contada em cinco quadros, ou seja, quadros que podem ser entendidos como capítulos. Cada um com sua importância, situações peculiares e tensões de Lampião e seu grupo

A peça teatral é contada em $3^{\text {a }}$ pessoa, tendo como personagens Maria Déa, que depois torna-se "Maria Bonita", Lauro, Lampião, Antônio Ferreira, Ponto-Fino, Moderno, Sabino Gomes, Corisco, Volta-Seca, Pai-Velho, Zé Baiano, Azulão, Pernambuco, Arvoredo, o Capangueiro, o vendedor de seguros, os 4 "cabras" de Corisco, o Tenente, os dois soldados, alguns Cangaceiros. Assim, a história é narrada no sertão, ambiente frequentado por Lampião e seus companheiros. 
A obra teatral Lampião, em tese, relata a história que ocorre a princípio com a personagem "Maria Déa" que após aceitar o convite, abandona os filhos e o esposo para seguir a vida com o cangaceiro. Destarte, com a chegada de Lampião à vila a procura de uma mulher que havia mandado uma carta para ele, e recado este mandado por Maria Déa para um dos seus cangaceiros, ocorre o encontro. Houve toda um suplício de seu antigo esposo Lauro, justificando para a mesma não tomar rumo para longe, cujos filhos e o próprio - esposo - necessitavam de sua presença, mas o instinto de aventura, incomodidade com sua vida pacata e vontade de querer conhecer algo diferente e novo repercute em sua forma de agir e com isso, opta em seguir Lampião. Nesse contexto, Maria Déa deixa este nome e ganha um codinome com o grupo de Lampião, passa a ser chamada de Maria Bonita. A peça proporciona desse modo características delineadas a valores identitários, guerra, autoritarismo e exclusão. $\mathrm{Na}$ qual, instigamos enveredar entre elementos prepotentes regidos com os seus opressores por suas mais variadas concepções. Neste sentido, nos inquietamos para responder a seguinte pergunta: Que ótica percorre nestes sujeitos?

\section{VOZES INTERCALADAS: RESQUÍCIOS DE AUTORITARISMO/ OPRESSÃO}

Em certos casos, é notável refletir como alguns escritores que recorrem aos personagens, ou seja, os utilizam como maneira de expressar, refletir sua ideologia e dar voz a certas mazelas e situações propícias de seu conhecimento e experiência. Com isso, alguns discursos, ambientes e espaços adotados pelos autores para os seus personagens carregam consigo uma reflexão de algum momento histórico, comportamento, acontecimentos e influência sociocultural que acabam por transparecer e ser identificado na obra. Assim Bakhtin complementa: "As palavras dos personagens, possuindo [...], de uma forma ou de outra, autonomia semântico-verbal, perspectiva própria, sendo palavras de outrem numa linguagem de outrem, também podem refratar as intenções do autor e, consequentemente, podem ser, em certa medida, a segunda linguagem do autor." (BAKHTIN, 1990, p. 119).

A maneira como o escritor expressa-se condiz, mesmo que subjetivamente, com algum acontecimento ou momento que pode retratar a intenção do autor e suas peculiaridades encontradas em sua obra. A sua forma de expressar acaba por transmitir a sua linguagem, que tanto pode retratar sua realidade individual, como também a realidade vigente da época, através do seu texto/contexto. Expressando o seu tempo e possibilitando um mundo artístico por meio da narrativa e dialogando com a uma ótica crítica, pois "a personagem não encontra espaço na dicotomia ser reproduzido/ ser inventado. Ela percorre as dobras e o viés dessa relação e aí situa a sua existência.” (BRAIT, 2006, p. 12).

Podemos perceber a influência existente entre a possível corroboração do contexto para formar o realismo do texto em sua forma integra. Que serve como pano de fundo, como camuflagem para a real intenção que o escritor quer perpassar. O autor cria ou modela o personagem em suas mais variadas intenções e em suas mais variadas dicotomias. Já que estes personagens coadunam-se de significações e constroem-se de inúmeras vozes intercaladas de opressão, exclusão, cultura e relações sociais. Neste norte, a passagem complementa: "Uma crítica que se queira integral deixará de ser unilateralmente sociológica, psicológica ou linguística, para utilizar livremente os elementos capazes de conduzirem 
uma interpretação coerente. Mas nada impede que cada crítico ressalte o elemento de sua preferência [...]" (CANDIDO, 2000, p. 7).

Dessa forma, há toda uma influência para a criação de uma obra e suas ideias, trazendo elementos que compõe a obra, seja o aspecto social, seja histórico,seja de miséria, seja de isolamento e abandono que "Virgulino Ferreira da Silva, terceiro filho de uma família de nove irmãos, se vê diante de um imbróglio que mudará radicalmente sua vida" (DANTAS, 2008 , p. 6). O chefe do cangaço pode ser visto como ingrediente para a construção de personagens fictícios dentro e fora da matéria literária. Com isso, percebemos a relação e envolvimento entre a identidade e a literatura, já que investigamos a imagem de Lampião e seus companheiros dentro do ambiente literário. É oportuno observar a relação estreita entre a literatura e a sociedade que colabora e abre espaço para a construção da figura de Lampião.

Nessa linha de pensamento, o enredo permeia-se de acontecimentos, atos e falas dos personagens que fragmentam sua personalidade. No primeiro quadro ocorre uma breve introdução, o princípio de uma conversa entre Maria Déa e seu antigo esposo Lauro e, dentre seus diálogos, a personagem aponta para um acontecimento na vida de Lampião, cuja fatalidade marcou a sua vida, mas esta não entra em detalhes e apenas comenta por cima, conforme aponta o trecho abaixo: "Maria Déa - Não rogue praga a quem você conhece, Lauro. Demais, tudo que você está dizendo é mentira. Lampião viveu em paz até à idade de 16 anos, e só entrou no cangaço porque a polícia matou o pai dele. Que é que um homem pode fazer, se não se vingar? (Escuta). Os tiros pararam... (QUEIROZ, 2005, p.19)"

O trecho acima contribui para atestar o vínculo deste com o cangaço, já que o próprio Lampião, o personagem, não tivera escolha senão o de seguir esse caminho do crime, devido a certos acontecimentos em sua vida, os quais o colocaram nesse meio. Nessa ocasião, "Lampião é uma vítima do seu meio" (BARROSO, 1930, p. 11), mas este personagem, mesmo sendo uma "vítima" social, não é induzido pelos governantes, pelo contrário, torna-se um ser capaz de conduzir sua vida e suas condições. Sendo assim, percebemos que Lampião cogita não só de um acontecimento drástico percorrido na sua vida que fez-lo adentrar nas veredas do cangaço. Convoca-nos a perceber, segundo a passagem da obra, como a personagem masculina foi repreendida pelo contexto sócio-político, pois as ações proliferadas pelo cangaceiro nada mais são do que uma (re)ação perante a violência calcada em sua vida e percorrida pelas ações dos policiais para/com sua família. Notamos que a personagem Maria Déa, demonstra conhecer de certa maneira a história do personagem Lampião e suas apreensões de vida.

Nesse contexto, tomamos como importante ressaltar a identidade de Lampião e sua família, como são acontecimentos fragilizados. O marido (antigo) de Maria Déa contrapõe a imagem de Lampião com outra versão, conforme:

Lauro - Muita vez já largaram os rifles e estão sangrando o povo a ferro frio... (Voltando ao assunto interrompido, exaltadíssimo, com pavor crescente.) Não, o caso de Lampião não foi como você está dizendo. Ele começou matando um vizinho, por causa de uma cabra que lhe comeu o roçado. Pelo malfeito dum bruto, tirar a vida dum cristão.... Assim foi que começaram, os três irmãos, o pai, e ele. (QUEIROZ, 2005, p.20). 
É relevante esclarecer que esse comentário não se enraíza, e se detém em definir o que foi feito por Lampião ou deixado de fazer para torná-lo assim, mas mostrar os pontos que unem e interligam aspectos, peculiaridades que acompanham o personagem Lampião. Percebemos como a imagem de Lampião possui suas versões e como são implantadas pelos personagens no decorrer da obra, mostrando de certa maneira uma mistificação da figura de Lampião.

De um lado, possui a versão de Maria Déa, mais especificamente vendo Lampião como vítima da situação; e o outro lado uma versão de Lauro como bandido, como criminoso. Conforme apresenta a passagem de Lauro denegrido de maneira a criticar Lampião na peça. "Lauro - Não, Silvino era bom, nunca fez perversidade à toa; e tirava para dar aos pobres. Mas Lampião é um assassino miserável, bebedor de sangue inocente. "(QUEIROZ, 2005, p. 19). Na qual as construções acabam por possibilitar em Lampião uma Identidade fragilizada, no sentido de recortada e dividida perante a bondade e a maldade cujos olhares permeiam-se de uma exclusão paradoxal. Ou seja, para Maria Déa o autoritarismo sofrido propicia sua condição no cangaço como também em Lauro a concepção que o mesmo já habita as hastes do furto e roubo como elemento inato; e excluso do olhar idôneo acatado de bondade. Nesse contexto, Lauro em sua concepção, relata uma informação sobre Virgulino Ferreira a este mundo do cangaço:

Lauro - [...]. Aquele bandido medonho, que pior não pode haver até o dia do Anticristo? [...]. Toda a vida se soube: Antônio Silvino foi ser cangaceiro por desgraças da vida. Lampião entrou no cangaço porque só dava pra isso, que era ladrão e assassino de nascença. Mas há de ter meu fim, tão certo como tem Deus no Céu. (QUEIROZ, 2005, p. 18-19)

Acaba por ser importante e perceptível recordar que Lampião adentra no cangaço por motivos direcionados à sua família. Dessa forma, acaba por ter perdas irreparáveis como a morte de seu pai, acarretando uma lacuna em sua vida, em sua família. Logo permanece neste meio de vida, com suas leis e formas de ver o mundo e as demais pessoas, essa é apenas uma possível versão. Assim, podemos fazer uma ponte de ligações, de aproximações da fala de Maria Bonita/Lauro com a vida de Lampião.

Diante disto, a imagem social mencionada de Lampião e demais cangaceiros, possui um entrave entre uma identidade sofrida, oprimida, se tornando produto de um meio e maltratado perante o sistema político que busca "justiça” perante as suas leis. Vale ressaltar que a personalidade e ações de tais personagens (Maria Déa ou Maria Bonita e Lampião), muitas vezes, são resultado de sentimento de vingança e do desejo de fazer justiça perante uma sociedade dominada pelos grandes patrões que mandavam nas terras, nas leis e tinham, portanto, forte influência política. Diante de tantas desigualdades e injustiças, alguns sertanejos adentravam em "grupos de justiceiros" como uma forma de sobrevivência e reação ao sistema sociopolítico vigente em sua região. Consoante isto, Queiroz aduz:

[...] fala do cangaço, tende a interpretá-lo como a formação de grupos de indivíduos, no Nordeste seco, que, semiconscientes da situação de opressão das ca- 
madas inferiores, sob o domínio dos coronéis, arvoram-se em defensores dos injustiçados. Por isso lutavam contra a exploração do homem pelo homem, depredavam e roubavam, chegavam a assassinar, porém por uma justa causa, a fim de dar algo aos necessitados e de abalar uma estrutura social, econômica e política abominável e desnacionalizante. (1986, p. 65)

Nota-se uma ótica emergida para a conduta de ser cangaceiro e estereótipos constituídos socialmente para a sua construção, já que diversas perspectivas são convocadas para este fértil campo literário. Percebemos algumas características identificadas no protagonista, sendo construída através do seu discurso. Até mesmo este manifesta sua posição mediante à sua própria identificação perante o enredo. A personagem fala do adquirimento da força, da maneira implícita e soberana para a construção do seu nome. Nome este que não surge e é dado de forma tradicional, burocrático e convencional e sim por sua garra, por suas ações e batalhas exercidas para ganhar tal identificação com toda essa "força" carregada por esse. Além do mais, é conhecido também por sua atuação marcante como cangaceiro perante a sociedade e política vigente no enredo. Conforme complementa a passagem:

Lampião - O finado Imperador batizou-se por Pedro, mas era tratado de Majestade. Pois a minha majestade é o nome de Lampião! No jornal não me chamam o Rei do Cangaço? Saio escrito no jornal... (Faz um gesto que abrange a todos.) ...todo mundo leu! E um cantador disse ainda que eu sou o Imperador do Sertão. Era um cego que não enxerga a luz do dia, mas vê a luz que eu alumeio! Porque, na caatinga, Lampião é rei coroado! (Dirige-se a CORISCO.) [...] (QUEIROZ, 2005, p. 34)

Podemos entender como o contexto da obra retrata também veemências, ou seja, o sistema político que, na ficção, torna-se inimigo do personagem Lampião. Na qual este não apresenta qualquer intimidação com o governo. Ao deixar claro que busca paz, mas caso isso não aconteça, a guerra continuará sendo seu meio de levar e continuar a viver. Nesse ponto a personagem Lampião dialoga com a classe política, mantendo alianças e relações. Através do que foi discutido, o protagonista do enredo manda uma carta para o governo afim de uma trégua, conforme vista na passagem:

Lampião - Não estou pedindo favor dele! Não quero graça de ninguém O favor sou que faço, para não me chamarem mais de bandido e assassino. Mandei o tratado de paz. Com a minha mão assinei o papel e tudo que eu dizia nele era de coração aberto. [...] Lampião - Nesse caso, pior para eles. Se querem é guerra, eu de guerra não tenho medo. (Passa a mão pelo papo-de-ema cheio de dinheiro que traz à cinta. Ri.) Afinal, a guerra é só meio de vida que eu conheço. (QUEIROZ,2005, p. 67-68).

Nesse sentido, o poder e a dominação do governo exercido na obra tornam-se perceptível, já que o personagem Lampião toma como atitude, mandar uma carta para se instaurar 
a paz entre este e as autoridades. Logo, o personagem Lampião recebe o retorno em um jornal da cidade, entretanto não há harmonia e acordo do governo, aliás, retornam-se insultos e provocações para esse. Conforme A autora asserta

Lampião (afastando-a.) - Deixa que eu leio. (Lê melhor do que ela, mas não correntemente.) 'A audácia do bandido não conhece limites...O bandoleiro sanguinário se atreve a fazer propostas de paz ao interventor, tratando-o de potência a potência... O governo prepara enérgica represália à insolência de Lampião. Diz o interventor federal em entrevista ao nosso repórter que, para Lampião, a polícia pernambucana só tem duas respostas: bala ou cadeia... (QUEIROZ,2005, p. 71)

Percebemos como o retorno do governo não atende às expectativas do personagem, logo o que o mesmo havia dito "A guerra é só meio de vida que eu conheço. ” (QUEIROZ,2005, p. 67-68). Dessa maneira, observamos que a vigência do autoritarismo político, já que existe um acordo recusado e as ordens não são de paz como queria o personagem Lampião.

Notamos como o poder da classe dominante exerce e influência os caminhos percorridos pela classe dominada e, com isso, afeta a sociedade e a quem dela participa. $\mathrm{Na}$ obra não é diferente, pois o personagem Lampião acaba por se contrapor a decisão do governo e assume seu posicionamento perante a lei. Com isso, percebemos como o sistema político acaba por exercer uma função e impacto mediante aos que a obedecem e estão a par dela.

Nessa linha de pensamento, Lampião irá se posicionar mediante as ações do contexto político e logo impõe seu ponto de vista, sua forma, sua maneira de justiça com repressão a vinda da carta, conforme aponta o trecho:

Lampião - Já chega. (Amarrota o jornal devagar. Pausa.) Ah bem, então é assim. É assim que eles recebem a minha aberta. Com bandido não tem acordo.... Pois eles vão conhecer o bandido... Assassino, não é? Eles nunca viram antes o que seja um assassino. Mas vão conhecer agora... O estado de Pernambuco para mim só tem cadeia e bala...Pois vai ver o eu Lampião tem pra Pernambuco... [...] PontoFino - Lá isso é. Polícia não quer acabar com cangaceiros. Eles vêm a uma légua de distância e a gente já está escutando o estalo da corneta. Querem que a gente se aquiete, ou vá para longe pra eles não serem obrigados a brigar. (QUEIROZ, 2006, p 71-72)

Percebemos a revolta do personagem Lampião com o sistema político, na qual a personagem Lampião e um de seus capangas comentam do governo e sua ingerência política mostrada em sua resposta ao pedido de paz de Lampião. Tanto Lampião, quanto seu bandoforam detidos e mortos através do governo, ou seja, a polícia. Diante disso, a polícia acaba em pôr fim em aproximadamente 20 anos do cangaço de Lampião. Nessa passagem da obra, percebemos o momento do ataque da polícia a si e seu bando: 
Lampião atira fora a tigela, salta para apanhar o fuzil, na tenda. Uma bala o atinge no rosto e ele cai, de bruços. Uma rajada de metralhadora varre o acampamento dos fundos; vêem-se vultos dos cangaceiros que se levantam e tentam correr, às tontas, mas caem, fuzilados. Gritos, pragas, gemidos. Maria Bonita corre para Lampião, caído. [..], O tenente. - Trouxe o facão? E o sal? (O soldado baixo a cabeça, afirmativamente.) Pois então corte as cabeças. (QUEIROZ, 2005, p.120-121)

Nesse contexto, a morte do personagem Lampião resgata uma imagem findada na morte também de Maria Déa - como o elo de acontecimentos e situações da vida de Lampião que caracterizam a obra em seus mais variados momentos. A nuance encontrada de certas ações do sistema governamental e até ao acerto de contas da polícia com Lampião e das mortes geradas, além de outros pormenores citados na análise acima proposta. Como também da personalidade do protagonista culminam num enveredar de um enredo revestido de atitudes e repressões encontradas na ótica da peça teatral.

\section{CONCLUSÃO}

Sendo assim, compreendemos que existe a oscilação do autor em refletir aspectos que nos fazem perceber que há intenções do mesmo, como também encontrar a linguagem objetiva e intencional, na qual é encontrado de forma simples o discurso de quem o escreve e este refrata a fala do personagem, pois "[...]. Cada enunciado é um elo na corrente complexamente organizada de outros enunciados." (BAKHTIN, 2003, p. 272). Diante de um estudo teórico-analítico ocorreu a análise mediante questões sobre resquícios de exclusa e autoritarismo com os cangaceiros que coabitam este espaço Racheliano.

Nessa linha de pensamento, o objetivo foi em fazer uma análise, investigando as categorias citadas com foco na interpretação das personagens na obra Lampião (2005) de Rachel de Queiroz. Este trabalho tem o intuito de despertar indagações e ensejos acadêmicos e investigativos. Buscamos, para a interpretação do estudo, discursos que propiciam e induzem/conduzem uma contribuição ou marcas da sociedade perante as suas convicções. Nesse contexto, o estudo feito não se fixa, pois o teor debatido não contém limites e está continuamente aberto a releituras neste fértil campo dos estudos na linguagem.

\section{REFERÊNCIAS BIBLIOGRÁFICAS}

MOISÉS, Massaud. A criação literária: prosa I. São Paulo: Cultrix, 1997.

BUENO, Luis. Uma história do romance de 30. São Paulo/Campinas: Edusp/Unicamp, 2006.

BAKHTIN, Mikhail. Estética da criação verbal. 4.a. ed. São Paulo: Martins Fontes, 2003.

BARROSO, Gustavo. Almas de Lama e de Aço. São Paulo: Melhoramentos, 1930. 
BAKHTIN, Mikhail. Questões de Literatura e Estética: A teoria do Romance. São Paulo: Hucitec, 1990.

BRAIT, Betch. A personagem. 8 - ed. - São Paulo: Ática, 2006.

CANDIDO, Antonio. Literatura e sociedade: estudos de teoria e história literária. 8 ed. São Paulo: T.A. Queiroz Editor, 2000.

DANTAS, Sérgio Augusto de Souza. Lampião entre a espada e a lei: Considerações biográficas e análise crítica. Natal-RN, 2008.

DÓRIA, C. A. O cangaço. São Paulo: Editora Brasiliense, 1982.

QUEIROZ, R. História do cangaço. São Paulo: Global 2ª ed., 1986.

QUEIROZ, Rachel de. Lampião. 5. ed. Rio de Janeiro: José Olympio, 2005.

Recebido em 19 de outubro de 2017 Aceito em 10 de dezembro de 2017 
